\title{
sciendo
}

\section{APPLICATION THE RESULTS OF ENERGY EFFICIENCY AUDIT PLANNING AND IMPLEMENTATION OF FISHING VESSELS MODERNISATION}

DOI 10.2478/ntpe-2018-0071

\author{
Dr. Eng. Marcin Szczepanek \\ Dr. Eng. Przemysław Rajewski \\ Maritime University of Szczecin, Poland \\ Doc. Ing. Dalibor Barta, PhD. \\ University of Žilina, Slovak Republic
}

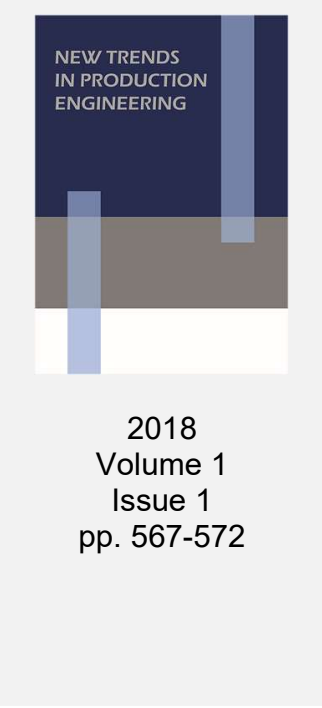

\begin{abstract}
The Energy Efficiency Design Index (EEDI) became mandatory for new ships as well as the Ship Energy Efficiency Management Plan (SEEMP) for all ships due to the MEPC 62 (July 2011) along with the adoption of amendments to MARPOL Annex VI by the Parties to the MARPOL Annex VI. This was the first legally binding climate change treaty to be adopted since the Kyoto Protocol. The Ship Energy Efficiency Management Plan (SEEMP), which has been obligatory since 2013, did not to cover fishing cutters but triggered the implementation of energy efficiency audits due to fishing limits, high fuel prices, and free freight market. A research team of the Maritime University of Szczecin conducted energy efficiency audits on several fishing vessels operated on the Baltic Sea and provided the results to the shipowners. On their grounds, the shipowners started seeking methods to reduce energy consumption. They began modernizing the vessels using the information collected in the reports on energy audits. Usually, the modernization process is performed in several stages. Apart from energy recovery installations, fishing vessels were furnished with the latest technologies aimed at the reduction of energy consumption and at making ships greener. The paper presents results of the said process at the selected fishing cutters operating on the Baltic Sea. The paper includes also the recommendations on the directions of the following stages of the audits.
\end{abstract}

Keywords: fishing cutters, energy audits, energy efficiency

\section{INTRODUCTION}

The development of an energy audit programme, dedicated for this specific vessels' group, aims at the improvement of energy efficiency for fishing vessels' operation by presenting to fishermen solutions reducing energy input while operating vessels. Shipowners, depending on their financial capability and investment policy, may select the simplest, operational solutions that do not require funding or more complex solutions requiring significant financial resources, but also considerably improving the vessels' energy efficiency. The first step towards adopting an exercise in energy efficiency on ships and to harvest the resultant savings is an energy audit. Energy audit basically consists of identifying core areas where conservation of energy can be done and then developing a programme for the same. The objectives of conducting an energy audit are as follows:

- to identify areas where there is a loss of energy due to reduced efficiency or incorrect operation, and cost savings resulting from having them corrected.

- to identify areas where new developed technology may reduce cost.

- to project the information without omitting anyone, to the buyer so that he can make a decision based on cost and profit.

- to improve the energy efficiency of the ship by saving fuel and also to reduce global warming by emission control and help go green.

An energy audit process on ships is conducted in the following steps: 
- data collection: All relevant data for the applicable machine is collected. The collection of data may be from mechanical means like counters, running hour indicators, event logs etc. In case these are not available, the duty engineers and operators are interviewed.

- condition evaluation: The condition of the machinery is evaluated and it is ascertained whether any overhaul or components replacement may improve its performance.

- economic alternatives: The audit will also inform the owner of the economic alternatives available and help them to make a decision.

- audit report: A final product of the audit (IMO, 2009).

\section{RESEARCH METHODOLOGY}

The assessment and the comparison of energy efficiency in different economic sectors play an increasingly important role in internal and international policies of most countries (IMO, 2009, Szczepanek, 2015). This is due to the intention to increase the level of economic competitiveness, ensuring country energy security and the improvement of the green image, and obtaining benefits from the reduction of carbon dioxide. The intention to reduce the fuel volume consumed by the Polish fishing cutters was the motive for carrying out the audits by the scientists of the Maritime University of Szczecin. In order to reach the said goal, the selected energy systems were audited and subject to the research. They covered the representative sample of ten fishing vessels.

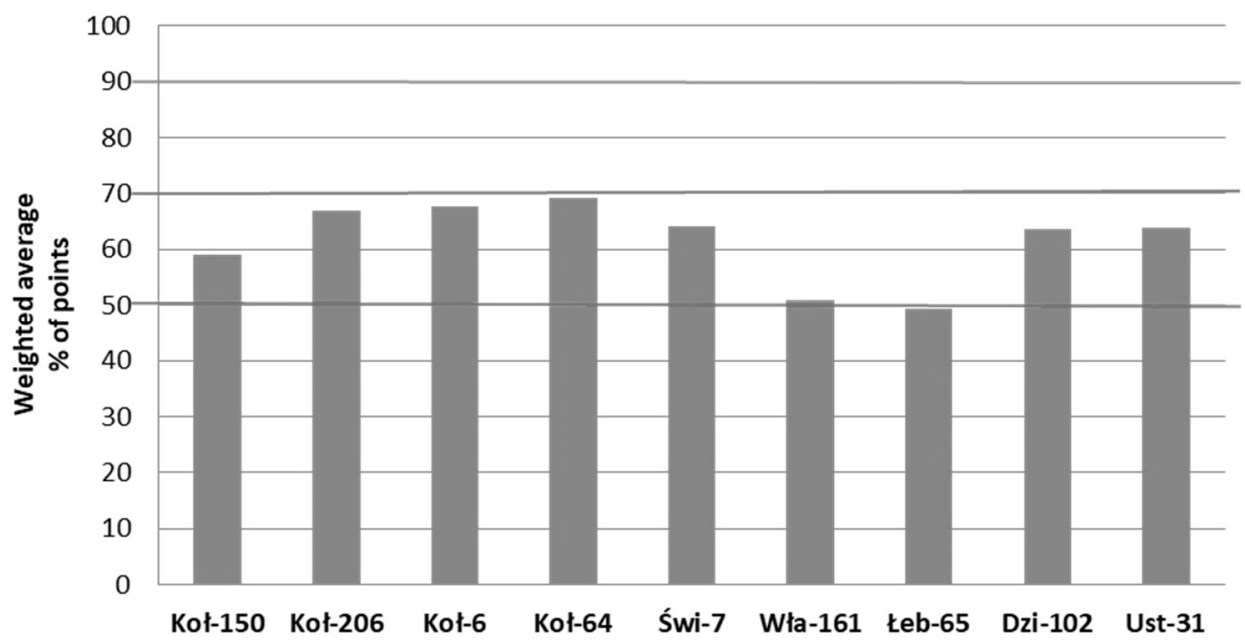

Fig. 1. The weighted average of percentage of gained points in every area of audits and the technical condition of the vessels.

Source: own elaboration

Based on the conducted research, the vessels condition and efficiency were established. Figure 1 presents examples of the audits' results for particular groups of devices.(Notti et al., 2012) As it may be noticed, one of the vessels, at the adopted weights and evaluation criteria, obtained the result specified as bad condition. Remaining vessels characterize with an average condition. One vessel missed one percentage point to be identified as good condition vessel. The audit results indicate areas where one may find potential to improve the energy efficiency of the fishing cutters. The research results' analysis of the operational power systems of the Polish fishing fleet (Behrendt 2014) allowed for an assessment of energy consumption for particular energy receivers (with respect to $100 \%$ chemical energy in fuel) (Jafarzadeh et al., 2016, Notti et al., 2012):

- Main drive $60-75 \%$.

- Fishing gear (hydraulic drive) 10-15\% (Rajewski et al., 2014)

- Electrical equipment 2-15\%. 
MODERNISATION BASED ON THE AUDIT RESULTS ON A SELECTED FISHING CUTTER Due to the established scope of works, two goals shall be obtained. The first one included the improvement of the navigation safety and the workplace safety. The second goal, significant from the financial point of view, referred to the improved energy efficiency of the vessels. Every step of the modernization process aimed at combing both goals as well fulfill the requirements of classification societies Polish Register of Shipping (PRS, 2010).

\section{Hull modernization}

Fishing cutters happen to perform fishing operations in harsh weather conditions, when the possibility of pouring the deck stormy wave is a direct threat to the life of people in that area (sweeping by a wave). In order to mitigate that risk and threat, it was decided to raise the forebody by $800 \mathrm{~mm}$ and add the bulwarks of the height of $900 \mathrm{~mm}$. Due to that solution, the fishermen working in that area obtained a fixed and stable protection against wind and waves. The scope of the forebody modernization covered also the hatch replacement (from the shelter deck to the working deck and from the working deck to storage area No. 2) with the hatches that would prevent a person from falling onto the lower level. In order to improve the safety and maintain the lateral stability (reduce inclination), the keel was widened along the entire length by $70 \mathrm{~mm}$ and the steel elements were replaced with lighter ones (between board winch support on the stern and the bow). Unnecessary steel elements were removed from the afterpeak which resulted in lowering the center of gravity of the ship. The electricity system and the sea water system were installed from afresh. Due to the renovation of the electricity system, the probability of electrical leakage was decreased. To reduce the towing resistance, shipowners obtained permission to make alterations to the vessel and to add 4GT to build a bulbous bow. Based on the model tests, it was assumed that the towing power (improvement of the hull energy efficiency) should equal from $5 \%$ to $10 \%$ depending on the trim and vessel speed. The bow should also transfer the center of buoyancy towards the bow allowing for optimizing trims so as to make maximum use of the bow parameters. The characteristic of towing resistance for various loading conditions is shown in Figure 2.

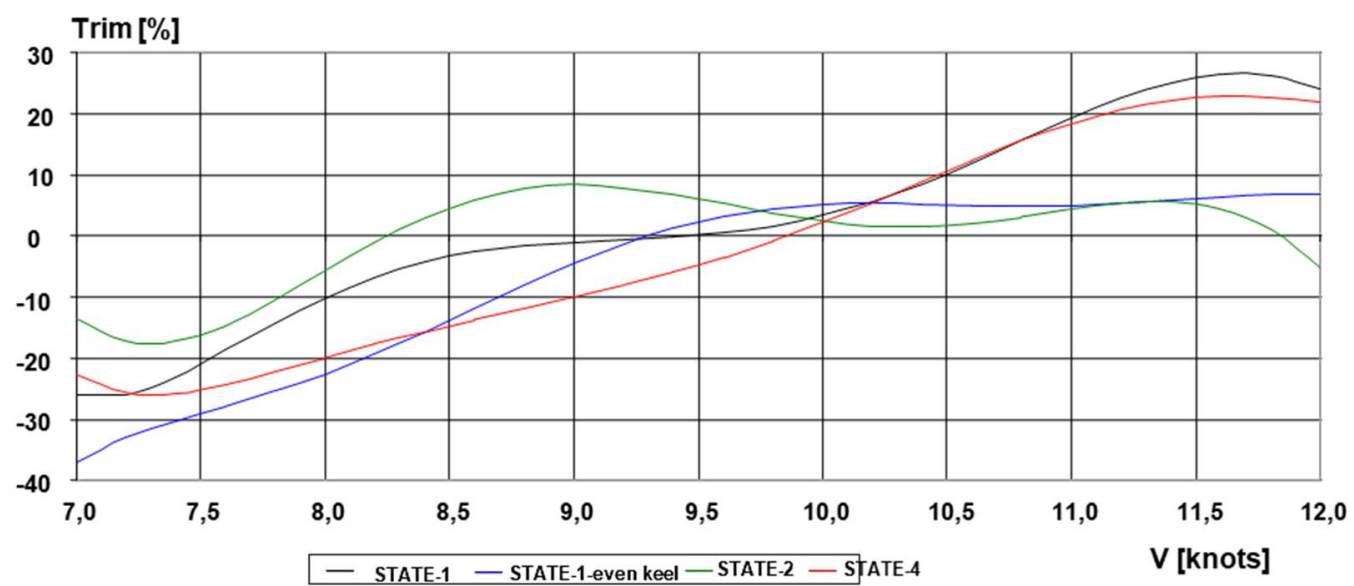

Fig. 2. Towing resistance curves for various trims of the hull.

Source: (Behrendt 2014)

Resistance curves in Figure 2 confirm that the redesigned part of a hull with a bulbous bow has significantly lower values of resistance. For speeds over 9-9.5 knots the towing power was reduced in all conditions of loading, and for conditions of loading with a trim by the stern, the difference of towing power before and after conversion reaches $25 \%$. This corresponds, for a speed of $12 \mathrm{knots}$, to a difference in towing power of up to $80 \mathrm{~kW}$ for STATE-1 (departure from a port). In addition to the above measurable advantages, the use of bulbous bow resulted in better attenuation of the bow wave, and due to lengthened underwater part of the hull, improved maneuvering abilities, that is course keeping stability. The installation of a thruster increases vessel's maneuverability, remarkably shortening the time required for harbour maneuvers from 40 to 5 minutes. The bow thruster GT 750, with a power of $75 \mathrm{~kW}$ and thrust 
$1125 \mathrm{kG}$, is mounted in a steel duct. Tests have confirmed that the use of a bulbous bow and thruster reduced fuel consumption by up to $10 \%$ in free sailing, therefore with a daily fuel consumption at the level of 2400 litres, resultant savings reduced total operating costs the positive financial result is significant. In order to make maximum use of the higher energy efficiency of the hull, one should aim for the sailing with trim at the stern. The bow thruster was incorporated into the existing hydraulic system. A control system needed to control the device from the bridge was designed and constructed. A lubricating system for the bow thruster transmission gear was also installed. One of its functions included pouring and drying with lubricating oil.

\section{Fish catching and transport}

A following stage of the modernization process was to adjust the fishing cutter to transport fish in bulk in the storage area which was redesigned and rebuilt. The area was divided into seven separately thermally insulated tanks (Fig. 3). The water temperature in the tanks equals to $-5^{\circ} \mathrm{C}$ (http://heinenhoman.com/).

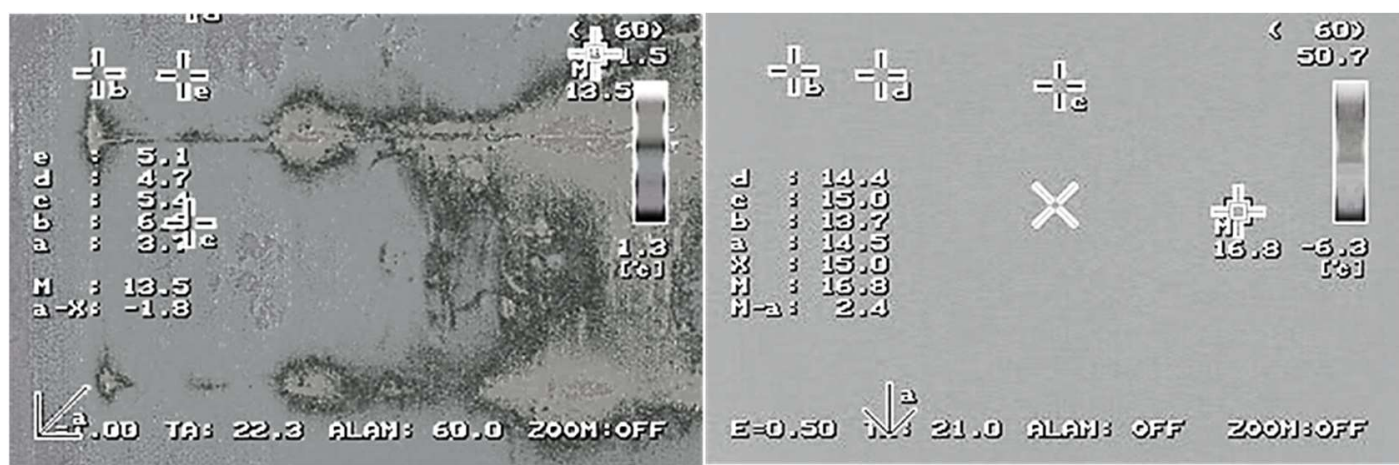

Fig. 3.Thermal image of the bulkhead between the engine room and RSW tanks before (left)

Source: (photo of the author) and after modernization (right side).

This catch storage system, namely the Refrigerated Sea Water (RSW), is an effective and cost-saving method of preserving the catch until offloading ashore or further processing onboard (Thomas et al., 2009). Fish quality remains unchanged. The traditional method of discharging the net pulled onto the trawl deck or using a side winch to do so may result in crushing fish and may require 2-3 persons to handle. Fish is provided to the sorting machine and to the RSW tank by a pump (impeller pump) and therefore the volume of mechanically damaged fish is lower and the number of people need to perform this operation is reduced. Given the above, the authors proposed to install a mobile pump hydraulically driven by the existing hydraulic power system. An impeller pump with the capacity of $300-1500 \mathrm{~m}^{3}$ of water per hour was engaged. The pump (Fig. 4) is hydraulically driven and is equipped with a rubber hose reel $(\varnothing 300)$ and a reel for hydraulic drive lines.

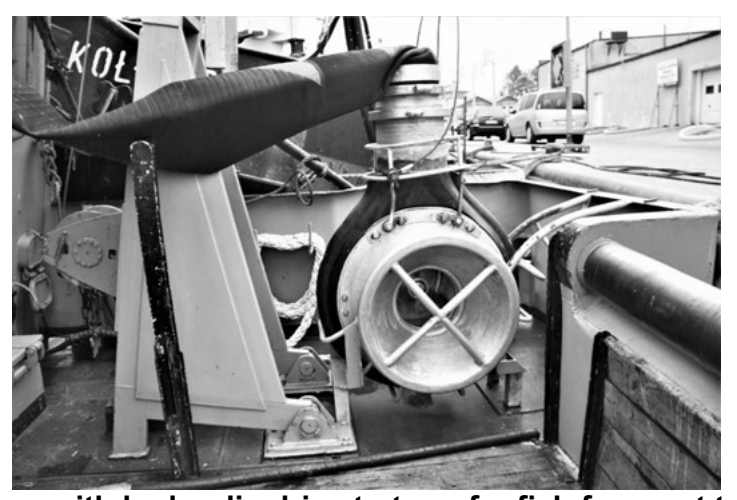

Fig. 4. Impeller pump with hydraulic drive to transfer fish from net to sorting machine. Source: (photo of the author). 
For lowering and lifting the pump, a small auxiliary crane was mounted (DOR 750). There are also devices mounted to transfer the catch and the water directly from the trawl net to the working deck (main deck) by a rubber hose. Then fish is fed to the separator where unnecessary seawater is filtered. At the next stage, fish is provided onto the lower working deck. There is a system for fish unloading installed. It is designed to unload fish from "wet" RWS tanks to the shore using the vacuum device (Fig. 5).

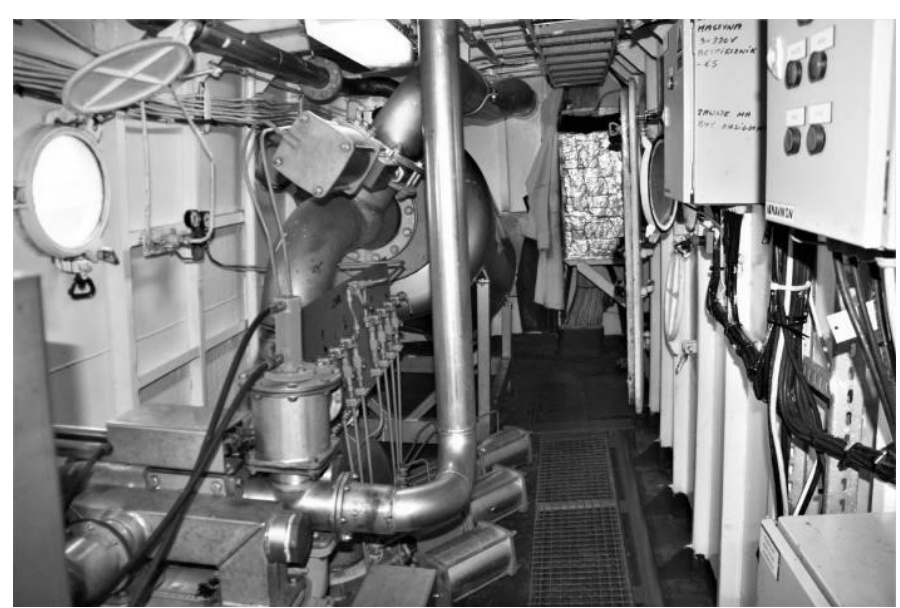

Fig. 5. Vacuum system for fish transport from RSW tanks to tanks onshore. Source: (photo of the author)

The adopted solutions required installing a new chilling system to support the RSW system along with GRASSO piston compressors, shell-and-tube condensers and RSW chillers using $\mathrm{NH}_{3}$ as a refrigerant, and a system forcing the circulation of chilled water in tanks. Upon the satisfactory completion of that modernization stage and tests, the vessel was put into operation. During catching fish, the adopted solutions proved to be suitable and accurate.

Summary

The total cost of the modernization of the mechanical and hull part equaled to PLN 2.7 million. During the audit, the authors compared the option of improving the fishing efficiency for the comparable cutters in terms of dimensions and drives' power and equipped with various navigational devices (of various age) to seek for fish and fishing operations. The difference reached even up to $26 \%$. As a result of the analysis, the shipowners cooperating with the authors decided to replace navigational and fishing devices with the newest and technologically developed ones, including specialized navigational and echolocation software. The cost of same equaled to PLN 350000. As hydraulic pumps are relatively new and sufficient funds are unavailable, these elements have not been modernized.

\section{CONCLUSION}

As a result of the modernization process performed on the vessels, the crew safety improved as well as vessels' navigational safety. The audit carried out upon the completion of the modernization showed that all the adjustments and alternation contributed to the reduction of the energy consumption by around $10 \%$ while increasing fishing efficiency. Higher quality of fish delivered to the shore resulted in higher prices of marketed fish and consequently in a higher financial result. Given that the modernizations were co-financed by the Operational Programme "Sustainable Development of the Fisheries Sector and Coastal Fishing Areas 2007-2013", it was estimated that the expenses incurred by shipowners should reimburse no later than after 4 years (ROI), and in an optimistic scenario, even after 2.5 years. The energy consumption measurement in hydraulic systems proved that it indicated the advisability of the next stage of modernization related to the replacement of hydraulic pumps with less energy consuming multi-piston pumps. The implementation of a variable speed control system for the hydraulic pumps should also be considered. According to the calculations, the reduction of 
energy for passive hydraulic oil flows allows decreasing energy consumption by additional 6 to $10 \%$.

\section{ACKNOWLEDGEMENTS}

This research outcome has been achieved under the research project no. 2/S/IESO/2018 financed from a subsidy of the Polish Ministry of Science and Higher Educations for statutory activities of Maritime University of Szczecin.

\section{REFERENCES}

Rajewski P., Behrendt C., Klys O. (2014). Modernisations Polish fishing vessels on the example of the cutter DZI-102 Scientific Journals of the Maritime University of Szczecin, Vol. 40 Issue: 112, pp. 17-22.

Polish Register of Shipping. (PRS) (2010). Documentation of the classification society for the $\mathrm{DZI}-102$.

IMO (2009). Guidance for the development of a Ship Efficiency Management Plan. MEPC.1/Circ. 683, London.

EU Commission Directive, (2002) Nr. 2002/35/EC of 25.04.2002.

European Union Council Directive, (1997) no. 97/70/EC of 11.12.1997.

Behrendt C. (2014), Energy saving technologies for fishing vessels, Scientific Journals of the Maritime University of Szczecin, Vol. 39 Issue: 111, pp. 11-25

Thomas G., O'Doherty D,. Sterling D., Chin C. (2009). Energy audit of fishing vessel, Engineering for the Maritime Environment, Vol 224, part M, pp. 87-101.

http://heinenhoman.com/en/fisheries/fishing-trawler/fishing-vessel-refrigeration-systems/rswsystem/ [Accessed 29 May. 2018].

Szczepanek M.(2015). Factors affecting the energy efficiency of fishing vessels, Scientific Journals of the Maritime University of Szczecin, Vol. 42 Issue: 114, pp. 38-42.

Notti E., Buglioni G., Sala A. (2012). An energy audit tool for increasing fishing efficiency, International Symposium on Fishing Vessel Energy Efficiency, E-Fishing, Vigo, Spain,

Jafarzadeh S., Ellingsen H,. Aanondsen S.A. (2016). Energy efficiency of Norwegian fisheries from 2003 to 2012, Journal of Cleaner Production, Vol. 112, part: 5, pp. 3616-3630. 